\title{
Rights for students expanding
}

$\mathrm{n}$ a move that is being seen as progressive and as a partial solution to the problem of attrition of women in chemistry, Stanford University's chemistry department has recently announced a maternity leave policy for graduate students where none existed before (see Supplementary Information online). The department has decided not to wait for the university-wide policy that is in the works, which is likely follow a family-friendly course similar to that of the chemistry department.

Under the new policy, students are entitled to a 12-week 'accommodation period' - the same amount of time guaranteed under the US Federal Family and Medical Leave Act (FMLA). Beyond this, the student maintains her status as a student, which allows her to keep the health benefits and funding sources that may be dependent on that status. Less than a month after the plan was announced to graduate students, one person was already planning to take advantage of it.

Richard Zare, the department chair, was instrumental in putting this policy into place after receiving inspiration from his colleague Professor Geri Richmond of the University of Oregon. Without a policy, Zare says, a student doesn't know what to do. Should she take a leave of absence, giving up her student status and whatever funding, whether internal or external, she may have? With a clear policy, backed wholeheartedly by Zare, such a student now has an unquestionable right to focus on herself and her newborn without concerns about sacrificing her student status. Equally important, it is not necessary for a student to negotiate this leave with her advisor.

While noting that he believes that the new policy is undoubtedly a good step, Zare openly wonders whether it is sufficient. For instance, it does not address the safety issues that pregnant or nursing mothers face when working in laboratories. In this regard, it is not clear that any university has clear guidelines for pregnant or nursing mothers. Many schools, including Emory University, have adopted policies of 'job modification', whereby an employee may continue working, but outside the lab, where the risk of exposure is lessened. Mothers and their doctors shoulder the burden of making safety decisions, which are complicated by the fact that it can be difficult to find conclusive studies showing the risks of individual chemicals. Although the Occupational Safety \& Health Administration (OSHA) of the US Department of Labor has established occupational exposure limits for numerous hazardous materials, there are no general standards governing reproductive hazards. The state of California's OSHA office has issued a limited number of standards, including ones for lead, dibromochloropropane and ethylene oxide, that dictates that information concerning the reproductive risks to these specific chemicals (http://www.osha.gov/SLTC/reproductivehazards/ standards.html) be transmitted to employees.

The Center for the Evaluation of Risks to Human Reproduction (CERHR) is focused on providing up-to-date information about specific chemicals. The National Toxicology Program and the National Institute of Environmental Health Sciences established the CERHR to serve as an environmental health resource to the public and to regulatory and health agencies, including the National Institutes of Health. The CERHR conducts rigorous evaluations of the scientific literature by independent panels of scientists to assess the potential for adverse effects on reproduction and development from more than 30 agents, including methanol and acrylamide (http:// cerhr.niehs.nih.gov/CERHRchems/index.html). Although these evaluations do not provide recommendations per se, they are used to express concern, for instance about acrylamide, regarding the potential for adverse reproductive and developmental effects from exposures in occupational settings.

Once the student delivers the baby, the benefits for her and her newborn can be equally uncertain. Stanford has approximately 1,500 postdoctoral students, who, unlike graduate students, have in the past been granted pregnancy leave. However, insufficient childcare' is cited as a major issue facing Stanford postdocs, according to the Stanford University Postdoctoral Association (SUPD). They would like to see Stanford make affordable oncampus childcare available to postdocs. Indeed, campus daycare centers should offer a reduced rate for students and postdocs, or at the very least have a sliding fee scale based on family income.

Although the graduate school and postdoctoral periods represent a prime child-bearing time for a majority of academic scientists, it is obvious to anyone who has worked in a lab that few students begin or add to their families during this time. In a bit of a chicken-and-egg dilemma, it's unclear whether the presence or absence of policies like Stanford's new childcare accommodation policy contributes to keeping down the number of women in the sciences, or whether, in fact, that has more to do with the sheer number of years required to go through school, postdoctoral training and the ensuing 'tenure clock' period of highly focused work. But policies like these are undoubtedly a step in the intended direction both for Stanford chemistry students and more broadly, as they should cause other schools to revisit policies impacting scientists with families.

Note: Supplementary information is available on the Nature Chemical Biology website. 